\title{
Dynamic wettability alteration for combined low salinity brine injection and surfactant flooding on silica surface
}

\author{
Meysam Nourani ${ }^{1}$ (D) Thomas Tichelkamp ${ }^{1} \cdot$ Hamid Hosseinzade Khanamiri ${ }^{2} \cdot$ Trine Johansen $^{1} \cdot$ Ingrid Karlsen Hov $^{1}$. \\ Bartlomiej Gaweł ${ }^{1} \cdot$ Ole Torsæter $^{2} \cdot$ Gisle ye $^{1}$
}

Received: 19 March 2020 / Accepted: 16 June 2020 / Published online: 23 June 2020

(C) The Author(s) 2020 OPEN

\begin{abstract}
Experimental results of dynamic contact angle measurements of low salinity brine and combined low salinity water and surfactant flooding (LSW-SF) on silica surface are presented in this study. Dynamic contact angle experiments were carried out for four crude oil samples with low salinity brines and combined low salinity and sodium dodecylbenzene sulfonate (SDBS) solutions. Similar measurements with the same ion strength in presence of different cations, $\mathrm{Na}^{+}$and $\mathrm{Ca}^{2+}$, for low salinity injections and combined low salinity-SDBS solutions were also carried out to study the change in dynamic contact angles and wetting behavior. The presences of different cations change the initial contact angles in low salinity solution injections and show different dynamic behaviors in presence of different crude oils. The signs and values of the line tension to oil/water interfacial tension ratios have been calculated from the size dependence of the dynamic contact angle measurements on the silica coated quartz crystal microbalance sensors. Analysis indicates positive line tension values for low salinity brine systems and negative values for LSW-SF systems. Injection of surfactant solutions in presence of electrolyte prompts the spreading of the oil droplet over the surface, which is induced by interfacial tension gradient from the top of the oil droplet toward the contact line. The results indicated that spreading time, which is the required time for oil drop to gradually flatten out, is dependent on type of electrolytes and is a function of surface excess concentration of the surfactant.
\end{abstract}

Keywords Wettability alteration - Dynamic contact angle $\cdot$ Low salinity brine $\cdot$ Combined low salinity water and surfactant flooding $\cdot$ Spreading time $\cdot$ Line tension

On a world scale about two-thirds of the original crude oil in place (OOIP) cannot be recovered during the primary and secondary phases of oil production and remain in the reservoir, trapped in rock pores due to capillary trapping and poor sweep efficiency [1,2]. This consequences in a huge amount of discovered oil seized in the reservoir in spite of an existing production infrastructure. The demand to increase the recovery factor of the petroleum reservoirs at economically feasible production rates is the main motivation for the enhanced oil recovery (EOR) applications around the world $[3,4]$.

Surfactant flooding is among the most effective and widely applied EOR process [3-7]. The efficiency of surfactant flooding methods in EOR is often related to the reduction of oil/water IFT [6-8], while wettability changes of the reservoir rock from oil wet to more water wet conditions are considered to play an important role in microscopic oil displacement [9]. In addition, the alteration of wettability from oil wet to intermediate wet may modify

\footnotetext{
$\varangle$ Meysam Nourani, meysamn@alumni.ntnu.no | ${ }^{1}$ Ugelstad Laboratory, Department of Chemical Engineering, Norwegian University of Science and Technology (NTNU), Trondheim, Norway. ${ }^{2}$ Department of Geoscience and Petroleum, Norwegian University of Science and Technology (NTNU), Trondheim, Norway.
} 
the relative permeability and consequently affect the volumetric sweep efficiency [10].

Also applying of low salinity water flooding (LSWF) as an EOR process has widely been practiced since the water sources are available and comparatively cheaper among other practical advantages $[11,12]$. While the mechanisms of LSWF to increase oil recovery have not been verified completely yet, the laboratory core floods and field tests have shown that rock/fluid interactions as well as the solution and surface chemistry play important roles [13-17]. It is widely agreed that the EOR by LSWF is related to wettability alteration toward more water wet conditions [18, 19], which creates positive capillary forces and increases the microscopic sweep efficiency in heterogeneous pore systems [19].

By combining these two techniques, surfactant flooding and low salinity water injection, an EOR process has been introduced that can promote increase in oil recovery, compared to the methods on their own [20-22].

Wettability alteration can be probed by some quantitatively different methods such as contact angle, imbibition and forced displacement (Amott), and United States Bureau of Mines (USBM) wettability experiments [23]. This work presents the measurement of dynamic contact angles which is comprised by the moving fluid/ fluid interface with the rock surface over the time to characterize rock/fluid/fluid interactions in case of rock/ oil/brine system [24]. The contact angle measurement is based on an ideal surface, which is smooth in texture and chemically homogenous. As the reservoir rock samples are generally rough and can be chemically heterogeneous, the measurement of the contact angle by using rock samples requires a distinction between the true contact angle $\theta$, and the apparent contact angle $\theta_{\mathrm{a}}$ [25]. Thus, in this study to monitor the true contact angles during LSWF and LSW-SF, dynamic contact angle measurements have been performed on silica coated crystals to simulate the smooth and ideal surface of sandstone reservoir rock. The dynamic contact angle experiments were conducted using four crude oils with different components and the well characterized sulfonate surfactant sodium dodecylbenzene sulfonate (SDBS).

\section{Materials and methods}

\subsection{Brines}

Six different brines (low, medium and high salinity) were made and used for running the dynamic contact angle measurements. The first low, medium and high salinity solutions, termed $\mathrm{LS}_{1}, \mathrm{MS}_{1}$ and $\mathrm{HS}_{1}$, were prepared by dissolving $\mathrm{NaCl}$ (99.5\%, Merk, Germany), in milli-Q water. The second low and medium salinity brines, abbreviated $\mathrm{LS}_{2}$ and $\mathrm{MS}_{2}$, were made with the same ion strength of $\mathrm{LS}_{1}$ and $\mathrm{MS}_{1}$ by dissolving $\mathrm{CaCl}_{2} \cdot 2 \mathrm{H}_{2} \mathrm{O}$ ( $99.5 \%$ Merck, Germany) in milli-Q water whereas the second high salinity brine, $\mathrm{HS}_{2}$, was prepared with the same ion strength of $\mathrm{HS}_{1}$ by dissolving $\mathrm{NaCl}\left(99.5 \%\right.$, Merck, Germany), $\mathrm{CaCl}_{2} \cdot 2 \mathrm{H}_{2} \mathrm{O}(99.5 \%$ Merck, Germany) and $\mathrm{MgCl}_{2} \cdot 6 \mathrm{H}_{2} \mathrm{O}$ (99.5\% Merck, Germany) in milli-Q water. The composition of the synthetic high, medium and low salinity waters are listed in Table 1.

\subsection{Surfactant Solutions}

SDBS (tech., Sigma Aldrich) was used as received. Its critical micelle concentration has been reported 589 ppm [26, 27]. The surfactant was dissolved in LS and milli-Q water at concentration of $1000 \mathrm{ppm}$ for running the dynamic contact angle measurements.

\subsection{Crude oils}

The crude oils used in these experiments were from onshore and offshore fields in the Germany and North Sea, respectively. Acid and base content were measured by potentiometric titrations with an 809 Titrando (Metrohm, USA). The bulk composition of the oils was investigated by SARA (Saturates/Aromatics/Resins/Asphaltenes) fractionation as described by Hannisdal [28]. The densities of the oils were measured in a temperature scan from 15 to $60^{\circ} \mathrm{C}$ with a DMA-5000 (Anton Paar $\mathrm{GmbH}$ ) density meter. The viscosity of each oil was measured in a temperature scan between (20 and 80$){ }^{\circ} \mathrm{C}$ and at a shear rate around $10 \mathrm{~s}^{-1}$

Table 1 Composition of high and low salinity brines

\begin{tabular}{lllllll}
\hline Composition & $\mathrm{LS}_{1}$ Con. (ppm) & $\mathrm{LS}_{2}$ Con. (ppm) & $\mathrm{MS}_{1}$ Con. (ppm) & $\mathrm{MS}_{2}$ Con. (ppm) & $\mathrm{HS}_{1}$ Con. (ppm) & $\mathrm{HS}{ }_{2}$ Con. (ppm) \\
\hline $\mathrm{Ca}^{2+}$ & 0 & 1069 & 0 & 1445 & 0 & 1625 \\
$\mathrm{Mg}^{2+}$ & 0 & 0 & 0 & 0 & 0 & 128 \\
$\mathrm{Na}^{+}$ & 1839 & 0 & 2556 & 0 & 11,022 & 7864 \\
$\mathrm{Cl}^{-}$ & 2836 & 1891 & 3944 & 2555 & 17,006 & 15,379 \\
TDS & 4675 & 2960 & 6500 & 4000 & 28,028 & 24,996 \\
lonic strength (mol/L) & 0.08 & 0.08 & 0.11 & 0.11 & 0.48 & 0.48 \\
\hline
\end{tabular}


with a Physica MCR301 (Anton Paar GmbH). The properties of the oils are given in Table 2 [26].

\subsection{Dynamic contact angle measurements}

\subsubsection{General procedure}

In this study $\mathrm{SiO}_{2}$ (QSX 303, Q-sense) coated quartz crystal microbalance sensors were used as received. Prior to each experiment the crystals were rinsed with toluene (VWR, $98 \%)$ followed by milli-Q water. Next, the crystals were dried with air and placed in 20,000 ppm aqueous sodium dodecyl sulfate solution for at least $30 \mathrm{~min}$. Afterward the crystals were rinsed with milli-Q water and dried with air again [27, 29-32]. The custom-made crystal holder, Fig. 1a, was used to set the crystal horizontally stable inside the glass chamber and keep it submersed in solutions.

In most of the experiments, a clean and dry crystal was used for dynamic contact angle measurements whereas for a few experiments, crystals were aged in the crude oil for $48 \mathrm{~h}$ at ambient temperature and dried before starting the measurement. The prepared crystal was inserted in the holder while the crystal was flipped upside down. A multistep procedure was followed for measuring dynamic contact angle in different rock/oil/brine systems. These steps are discussed below in detail.

\subsubsection{Procedure of low salinity experiments}

Step (1): Depending on the type of the measurement, about $6 \mathrm{ml}$ of HS or MS brine solution was introduced into the glass chamber until the silica surface was submersed in the solution.

Step (2): Through the hooked needle, as shown in Fig. $1 \mathrm{~b}$, a crude oil drop was injected and then it was

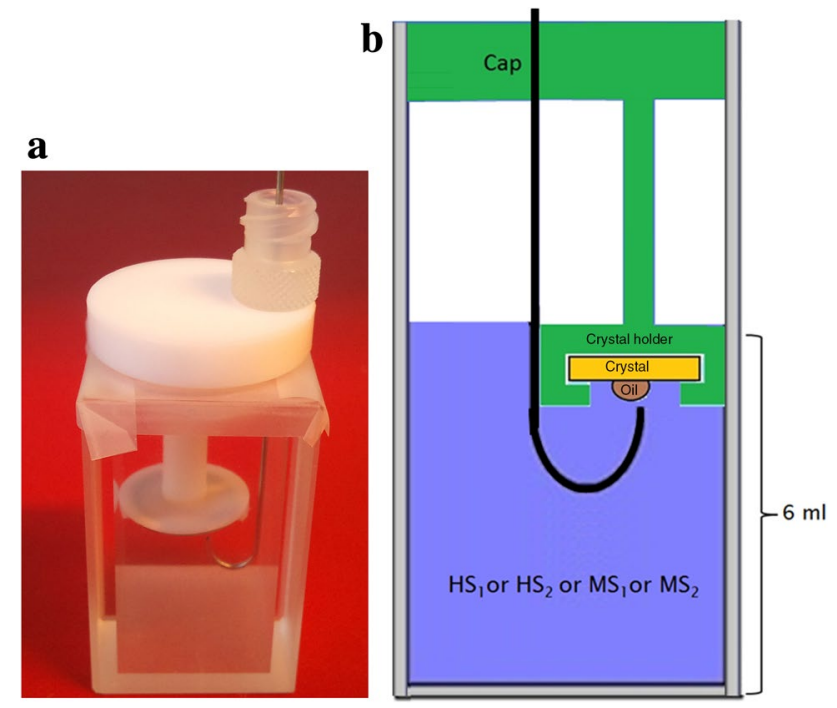

Fig. 1 a Left picture: The glass chamber and its custom-made crystal holder. $\mathbf{b}$ Right picture: The schematic of placing oil drop on the surface of silica crystal by hooked needle

released from the needle tip. Due to the lower density of oil drop, it rose upward until it approached into contact with the surface of the silica crystal.

Step (3): Surfactant or combined LS-surfactant solution or milli-Q water was injected by Atlas Syringe Pump (Syrris, UK) into the glass chamber whereas the injection rate was fixed at $1 \mathrm{ml} / \mathrm{min}$.

These three steps were repeated with different solutions for running LSWF and LSW-SF measurements as discussed below.

To investigate the effect of different cations on the change in dynamic wetting behavior during applying low salinity flooding, the following injection sequence
Table 2 Composition and properties of the crude oils (TAN/TBN = total acid/base number) $[26,27]$

\begin{tabular}{lllll}
\hline Composition (wt\%) & Crude A & Crude B & Crude C & Crude D \\
\hline Saturates & 61.2 & 73.9 & 52.5 & 82.5 \\
Aromatics & 32.4 & 22.7 & 34.6 & 16.7 \\
Resins & 4.9 & 2.6 & 12.7 & 0.7 \\
Asphaltenes & 1.5 & 0.9 & 0.2 & 0.1 \\
Physical properties & & & & \\
TAN (mg KOH/g) & 1.08 & $<0.1 *$ & 2.46 & $<0.1^{*}$ \\
TBN $(\mathrm{mg} \mathrm{KOH} / \mathrm{g})$ & $1.16 \pm 0.35$ & $0,56 \pm 0,14$ & $-{ }^{* *}$ & $0.18 \pm 0.03$ \\
Density $\left(\mathrm{g} / \mathrm{cm}^{3}\right.$ ) at $15^{\circ} \mathrm{C}$ and $60^{\circ} \mathrm{C}$ & 0.8582 & 0.8519 & 0.8909 & 0.8045 \\
& 0.8252 & 0.8204 & 0.8593 & 0.7703 \\
API gravity $\left({ }^{\circ} \mathrm{API}\right)$ & 33.4 & 34.5 & 27.3 & 44.3 \\
Viscosity (mPas) at $20^{\circ} \mathrm{C}$ and $60^{\circ} \mathrm{C}$ & 19.90 & 19.00 & 133.00 & 3.85 \\
& 4.07 & 3.48 & 23.10 & 1.52 \\
\hline
\end{tabular}

*Value below detection limit of the method

**Not detectable because of resin precipitation on the electrode 
Table 3 Final compositions of brines in dynamic contact angle measurements for low salinity injections

\begin{tabular}{lll}
\hline Composition & $\begin{array}{l}\mathrm{MS}_{1}-\mathrm{mQ} \text { water } \\
(\mathrm{ppm})\end{array}$ & $\begin{array}{l}\mathrm{MS}_{2}-\mathrm{mQ} \\
\text { water } \\
(\mathrm{ppm})\end{array}$ \\
\hline $\begin{array}{l}\text { Injection systems } \\
\mathrm{Ca}^{2+}\end{array}$ & 0 & 723 \\
$\mathrm{Mg}^{2+}$ & 0 & 0 \\
$\mathrm{Na}^{+}$ & 1278 & 0 \\
$\mathrm{Cl}^{-}$ & 1972 & 1277 \\
TDS & 3250 & 2000 \\
lonic strength (mol/L) & 0.055 & 0.055 \\
\hline
\end{tabular}

was applied for two MS brines, $\mathrm{MS}_{1}$ and $\mathrm{MS}_{2}$, and four crude oils.

Step (1): About $6 \mathrm{ml}$ of MS brine solution was introduced into the glass chamber.

Step (2): A crude oil drop was injected on the surface of the silica crystal.

Step (3): $6 \mathrm{ml}$ of milli-Q water was injected to dilute the MS brine.

The final compositions of brines for low salinity injections are listed in Table 3. The final amount of total dissolved solids (TDS) after dilution with pure water would be about 3250 and 2000 ppm for $\mathrm{MS}_{1}$ and $\mathrm{MS}_{2}$, respectively which are below the limit reported for low salinity water flooding (5000 ppm) [30].

\subsubsection{Procedure of combined low salinity and surfactant experiments}

Dynamic contact angle measurements during LSW-SF were conducted for four crude oils and two HS brines, $\mathrm{HS}_{1}$ and $\mathrm{HS}_{2}$, by following order.

Step (1): About $6 \mathrm{ml}$ of HS brine solution was injected into the glass chamber.

Step (2): A crude oil drop was placed on the surface of the silica crystal.

Step (3): To compare and discuss the results in context of total brine salinity and cation type, some experiments were run by injection of $4 \mathrm{ml}$ of $1000 \mathrm{ppm}$ SDBS solution in pure water and some measurements were conducted by injection of $4 \mathrm{ml}$ of the combined $\mathrm{LS}_{1}$-surfactant solution into the glass chamber. The final compositions of brines for surfactant flooding and combined low salinity and surfactant injections are listed in Table 4.
Table 4 Final compositions of brines in dynamic contact angle measurements for surfactant flooding and combined low salinity and surfactant injections

\begin{tabular}{llll}
\hline Composition & \multicolumn{3}{l}{ Injection systems } \\
\cline { 2 - 4 } & $\mathrm{HS}_{2}-\mathrm{SDBS}(\mathrm{ppm})$ & $\begin{array}{l}\mathrm{HS}_{1}-\mathrm{LS}_{1}- \\
\mathrm{SDBS} \\
(\mathrm{ppm})\end{array}$ & $\begin{array}{l}\mathrm{HS}_{2}-\mathrm{LS}_{1}- \\
\mathrm{SDBS} \\
(\mathrm{ppm})\end{array}$ \\
\hline $\mathrm{Ca}^{2+}$ & 975 & 0 & 975 \\
$\mathrm{Mg}^{2+}$ & 77 & 0 & 77 \\
$\mathrm{Na}^{+}$ & 4718 & 734,9 & 5454 \\
$\mathrm{Cl}^{-}$ & 9227 & 11,338 & 10,362 \\
$\mathrm{SDBS}$ & 400 & 400 & 400 \\
TDS & 15,397 & 19,087 & 17,268 \\
lonic strength (mol/L) & 0.29 & 0.32 & 0.32 \\
\hline
\end{tabular}

\subsubsection{Capturing of contact angles}

The contact angles were captured at brine-silica crystalcrude oil interface at room temperature $\left(22^{\circ} \mathrm{C} \pm 1\right)$ by using an Optical Contact Angle Meter equipped with a computer-controlled high-speed camera (CAM 200, KSV Instruments, Finland). The contact angle for an oil drop on a surface in a surrounding fluid of water is measured outside the oil droplet in the water [33]. Images were taken for each $2 \mathrm{~s}$ and contact angles were determined by image processing of the angles of the oil droplet profile by fitting the classical Young's equation as:

$\gamma_{o w} \cos \theta_{o w}=\gamma_{s o}-\gamma_{s w}$

where $\theta_{o w}$ is the contact angle between oil and water. $\gamma_{s o}, \gamma_{s w}$, and $\gamma_{o w}$ are the solid-oil surface tension, solidwater surface tension, and oil-water interfacial tension, respectively.

\subsubsection{Line tension determination}

The line tension is defined as the work of forming a contact line of unit length and considered as extra tensile force acting on the three phase line $[34,35]$. As the Young's equation has been derived without considering the effects of the three-phase contact line, line tension has been considered in the modified Young's equation as:

$\cos \theta_{o w}=\frac{\gamma_{s o}-\gamma_{s w}}{\gamma_{o w}}-\frac{\sigma}{\gamma_{o w}} \frac{1}{R_{d}}$

where $\sigma$ is the line tension of the three-phase contact line. $R_{d}$ is the radius of contact line [35]. Equation (2) shows that the oil-water contact angle depends on the drop size. Plotting of $\cos \theta_{\text {ow }}$ versus $1 / R_{d}$ can be depicted by measuring 
oil-water contact angle over time whereas the drop radius, $R_{d}$, is changing during the measurement.

Therefore, line tension, $\sigma$, can be calculated from the slope, $\frac{-\sigma}{\gamma_{o w}}$, of the plot. Unlike the situation of surface and interfacial tension, line tension can be positive or negative [36]. The sign of the line tension will be determined by the slope of the line; a positive slope will result in a negative line tension and a negative slop indicates a positive line tension [35]. Positive line tension recognizes as a compressive force which operates to minimize the total length of the three-phase contact line whereas a negative line tension would instruct an increase in contact angle with increasing drop size [37].

\subsection{Interfacial tension measurements}

Interfacial tension measurements were conducted between crude oil $A$ and dissolved surfactant at concentration of $400 \mathrm{ppm}$ in various $\mathrm{NaCl}$ brines. The salinity scan was conducted for a range of $\mathrm{NaCl}$ concentration ranging from $4000 \mathrm{ppm}$ to $20,000 \mathrm{ppm} \mathrm{NaCl}$. IFT values were measured at $22^{\circ} \mathrm{C} \pm 1$ with a Spinning Drop Video Tensiometer, SVT20 (DataPhysics Instruments $\mathrm{GmbH}$, Germany). A Fast Exchange Capillary (FEC 622/400-HT) was filled with the aqueous solution by a syringe and thereafter closed with a screw lid with PTFE septum. The capillary was inserted into the tensiometer and a single drop of the oil was injected into the capillary with a syringe. Rotation of the capillary was started and increased to gain a free and cylindrical or elliptical drop. The SVTS 20 IFT software was used to fit the profile of the drop and to calculate the IFT according to the method of Cayias, Schechter, and Wade (CSW) [26].

\subsection{Surface excess concentration determination}

The surface excess concentrations in $\mathrm{LS}_{1}, \mathrm{LS}_{2}, \mathrm{MS}_{1}$ and $\mathrm{MS}_{2}$ were determined at room temperature $\left(22^{\circ} \mathrm{C} \pm 1\right)$ by measuring the surface tension of a surfactant concentration series at air/water interface. Surface tension was measured using a Du Noüy Platinum Ring Tensiometer, Sigma 70 (KSV Instruments, Finland). The surface excess concentration calculated from the slope of the regression straight line of the linearly dependent region between the surface tension and surfactant concentration based on the following equation [38].

$\Gamma=-\frac{1}{R T} \frac{d \gamma}{d \ln C}$

where $\Gamma$ is the surface excess concentration, $\frac{d \gamma}{d \ln c}$ is the slope of the regressed straight line when surface tension plotted versus surfactant concentration, $R$ is the universal gas constant and $\mathrm{T}$ represents the absolute temperature.

\subsection{Displacement measurements}

Four displacement experiments were conducted for crude oil A by following order.

Step (1): Four Berea sandstone core plugs were extracted from two sandstone blocks. The plugs were first cleaned with methanol and dried in a heating oven at $60^{\circ} \mathrm{C}$ for 1 week. The dimensions, porosities, and corrected air permeability $\left(\mathrm{K}_{\text {air }}\right)$ were then measured.

Step (2): Irreducible water saturations $\left(S_{w i}\right)$ with two high salinity brines denoted $\mathrm{HB}_{1}$ and $\mathrm{HB}_{2}$, similar to high salinity bines used in dynamic contact angle measurements, were established by porous plate. The plugs were aged at $80^{\circ} \mathrm{C}$ for three weeks right after drainage by porous plate and then mounted into a core holder in a flooding rig. The oil relative permeabilities were measured at $\mathrm{S}_{\mathrm{wi}}$ before flooding experiments. The plug properties are listed in Table 5.

Step (3): Two low salinity brines $\left(\mathrm{LB}_{1}\right.$ and $\left.\mathrm{LB}_{2}\right)$, and low salinity surfactant solutions $\left(S_{1}\right.$ and $\left.S_{2}\right)$, were consecutively injected in core flooding experiments. Injection rate was maintained at $0.2 \mathrm{ml} / \mathrm{min}$. All the flooding experiments were performed at $60^{\circ} \mathrm{C}$ and a back pressure of 4.5 bara. Compositions of the brines in core flooding tests are given in Table 6 .

\section{Results and discussion}

\subsection{Low salinity brine systems}

Figures 2 and 3 show the dynamic contact angles for two low salinity brine systems with different cations $\mathrm{Na}^{+}$and
Table 5 Properties of the core plugs

\begin{tabular}{lcllllll}
\hline No. & Block \# & $\mathrm{L}(\mathrm{cm})$ & $\mathrm{D}(\mathrm{cm})$ & $\mathrm{K}_{\text {air }}(\mathrm{mD})$ & $\varnothing(\%)$ & $\mathrm{S}_{\mathrm{wi}}(\%)$ & $\mathrm{K}_{\mathrm{o}}(\mathrm{mD})$ at $\mathrm{S}_{\text {wi }}$ \\
\hline 1 & 6 & 9.94 & 3.80 & 309 & 15.5 & 23.3 & 233 \\
2 & 6 & 9.94 & 3.75 & 391 & 15.9 & 22.9 & 383 \\
3 & 14 & 9.89 & 3.82 & 34 & 15.6 & 23.5 & 41 \\
4 & 14 & 9.86 & 3.83 & 21 & 16.6 & 25.6 & 25 \\
\hline
\end{tabular}


Table 6 Composition of brines in core flooding tests

\begin{tabular}{llclc}
\hline Fluid & SDBS (ppm) & $\mathrm{NaCl}(\mathrm{ppm})$ & $\begin{array}{l}\mathrm{CaCl}_{2} \cdot 2 \mathrm{H}_{2} \mathrm{O} \\
(\mathrm{ppm})\end{array}$ & $\mathrm{TDS}(\mathrm{ppm})$ \\
\hline $\mathrm{HB}_{1}$ & - & 32,500 & - & 32,500 \\
$\mathrm{HB}_{2}$ & - & 30,875 & 1362 & 32,237 \\
$\mathrm{LB}_{1}$ & - & 3250 & - & 3250 \\
$\mathrm{LB}_{1}$ & - & 3087 & 136 & 3224 \\
$\mathrm{~S}_{1}$ & 500 & 3250 & - & 3750 \\
$\mathrm{~S}_{2}$ & 500 & 3087 & 136 & 3724 \\
\hline
\end{tabular}

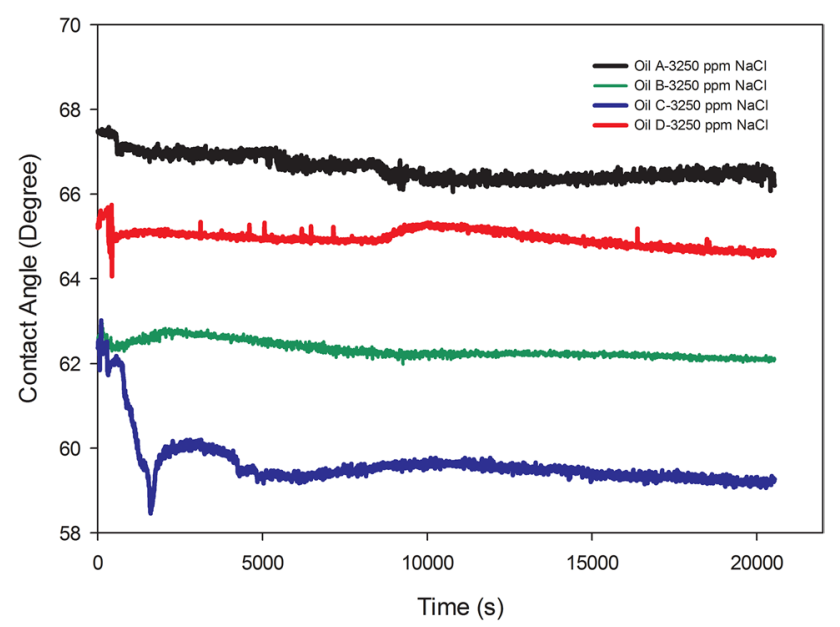

Fig. 2 Dynamic contact angles for four crude oils and low salinity brine system with $\mathrm{Na}^{+}$

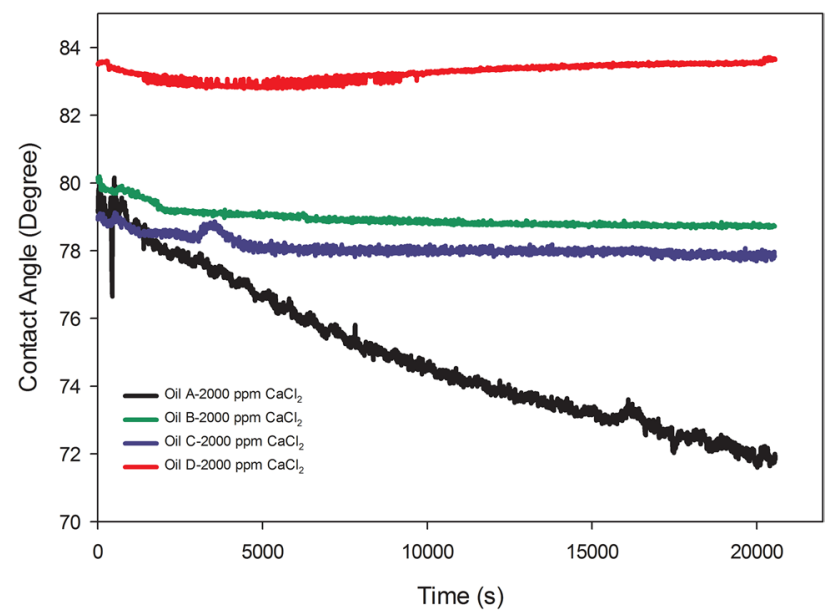

Fig. 3 Dynamic contact angles for four crude oils and low salinity brine system with $\mathrm{Ca}^{2+}$

$\mathrm{Ca}^{2+}$. Sodium low salinity system showed lower initial contact angles than calcium low salinity brine for all the crude oils. Linear equations were fitted to the plots of $\cos \theta_{\text {ow }}$

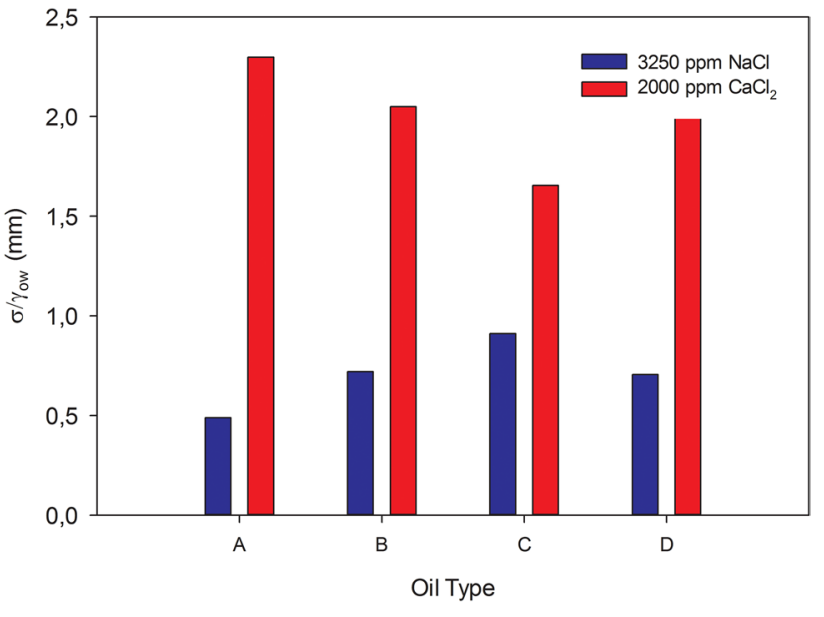

Fig. 4 Line tension to IFT ratios for four crude oils and low salinity brine systems with $\mathrm{Na}^{+}$and $\mathrm{Ca}^{2+}$

versus $1 / R_{d}$ data. Line tension to IFT ratios were calculated from the slope of the regressed lines. These ratios for low salinity brines with sodium and calcium are given in Fig. 4 . Moeini et al. [39] showed $\mathrm{Ca}^{2+}$ increases the IFT values. Therefore, higher line tension to IFT ratios for calcium low salinity brine indicates higher line tension values were obtained in presence of calcium. Saini et al. [24]. showed that the extent of line tension has a direct correlation with the oil/surface adhesion interaction. Thus, the calcium low salinity brine system shows higher adhesion between the oil and crystal surface than sodium low salinity system.

The higher initial contact angles and adhesion between the oil and crystal surface in the low salinity solution with calcium comparing to the sodium low salinity system can be explained by acting acid/base interaction in sodium low salinity solution and ion-binding mechanism in the calcium brine system. Above $\mathrm{pH} 2$, silica surface develops a negative charge and positively charged nitrogen bases can adsorb onto silica through a water film. The impact of the DLVO forces including electrical and van der Waals forces is most significant in stabilizing the thin water film between surface and crude oil in the presence of sodium low salinity brines [40]. Stabilizing this thin water film between crude oils and silica surface through acid/base interaction could be the reason of more water wet initial condition for the sodium low salinity system. $\mathrm{Ca}^{2+}$ ions act as a bridge between the surface-active components from the crude oil and the negatively charged silica surface [41] in the calcium low salinity system. As some of the water-soluble polar compounds in the crude oils can diffuse through the calcium water film and can be adsorbed onto the surface [42], the higher initial contact angles and adhesion between the oil and crystal surface were observed for the calcium low salinity system. 
The water wettability increased slightly over the time for all the crude oils and both sodium and calcium low salinity systems. According to Eq. 2, as the radius of the three-phase contact line, $R_{d}$, increases over time, contact angle will decrease when the line tension to IFT ratio is positive. Therefor the positive line tension to IFT ratios in Fig. 4 indicate wettability alteration toward more water wet conditions for both sodium and calcium low salinity systems.

Decreasing the salinity of brine due to injection of pure water during conducting of the sodium low salinity experiments, results the expansion of the diffuse double layer between the silica surface and oil interfaces which facilitates the release of organic materials and consequently increases the water wettability [43]. The intermolecular forces in presence of calcium comprise of van der Waals, electrostatic and hydration forces. The van der Waals forces are attractive, while electrostatic forces are repulsive between the interfaces. The hydration forces can be either a hydrophilic effect for a surface such as clean quartz or a hydrophobic effect for a surface with an organic coating. Combination of these three forces is identified as the disjoining pressure that tends to separate the oil/water and water/solid interfaces. The stability of the water film in the calcium low salinity systems is dependent on the magnitude of the disjoining pressure [42]. Dilution of calcium brine solution by injection of pure water, prompts the magnitude of repulsive forces against the attractive forces which results higher disjoining pressure and consequently more stability of the water film. Hence, the silica surface shows more water-wet condition in the calcium low salinity system by the lower contact angle values.

Presence of calcium causes higher adhesion between the oil and surface, but on the other hand, as the slope of $\cos \theta_{\text {ow }}$ versus $1 / R_{d}$ is higher for calcium, considering an equal change in $R_{d}$ will cause higher change of contact angle towards more water wet condition in calcium low salinity system than in sodium low salinity.

\subsection{Surfactant flooding and combined low salinity and surfactant injection systems}

As shown in Fig. 5, contact angle increased over time for both surfactant flooding $\left(\mathrm{HS}_{2}-\mathrm{SDBS}\right)$, and combined low salinity and surfactant injection $\left(\mathrm{HS}_{2}-\mathrm{LS}_{1}-\mathrm{SDBS}\right)$. However this increasing trend in contact angle measurement appears to contradict the general view that the wettability alteration to water wet condition is crucial to EOR [6], it has been reported as an indication for improving oil recovery by some researchers [44-46] and was related to reach a low IFT value below the critical spreading tension [47].

The increasing of contact angle in presence of surfactant can be explained by two mechanisms. The first

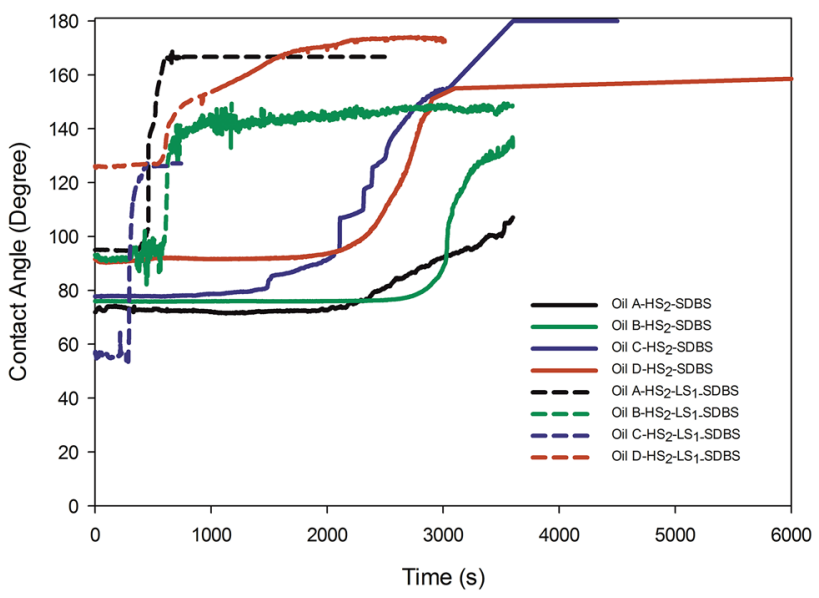

Fig. 5 Dynamic contact angles for surfactant flooding and combined low salinity $\left(\mathrm{LS}_{1}\right)$ and surfactant injection at calcium brine system $\left(\mathrm{HS}_{2}\right)$

mechanism is induced by a disparity in the surface and interfacial tensions at the three-phase contact line during the early-times [48]. Surfactant adsorbs at the brinelsolid and at the oillwater interfaces. Surfactant adsorption at these interfaces leads to decrease the brinelsolid surface tension and oillwater interfacial tension. Thus $\gamma_{s w}$, and $\gamma_{o w}$ are changing before drop spreading whereas $\gamma_{s o}$ is constant. The oil drop spreading is driven by the unbalanced capillary force on the three-phase contact line and the contact angle increases with time as the droplet spreads. The oil droplet will spread until the balance between the surface tensions at the three-phase contact line are restored [48].

The second mechanism of increasing contact angle is due to the Marangoni effect. As shown in Fig. 6a, the oil droplet surface area is larger at the edges; consequently, transferring of surfactant molecules from the aqueous phase to the oillwater interface is promoted at the droplet edge. Therefore, the surfactant concentration becomes much higher at the droplet edges relative to the top of the droplet, which reduces the IFT there. The resulting IFT gradient induces Marangoni flow from the contact line toward the droplet top $[48,49]$. Marangoni stresses induce extra shear stresses at the three-phase contact line. These induced shear stresses stimulate spreading of the oil droplet over the silica surface [49] as was shown in Fig. 6b.

The Marangoni flow is directly proportional to the IFT gradient and inversely related to the oil viscosity [50] as given by

$\frac{\partial \mathrm{U}_{\mathrm{z}}}{\partial \mathrm{r}}+\frac{\partial \mathrm{U}_{\mathrm{r}}}{\partial \mathrm{z}}=\frac{1}{\mu_{\mathrm{o}}} \frac{\mathrm{d} \gamma_{\mathrm{ow}}}{\mathrm{dr}}$ 


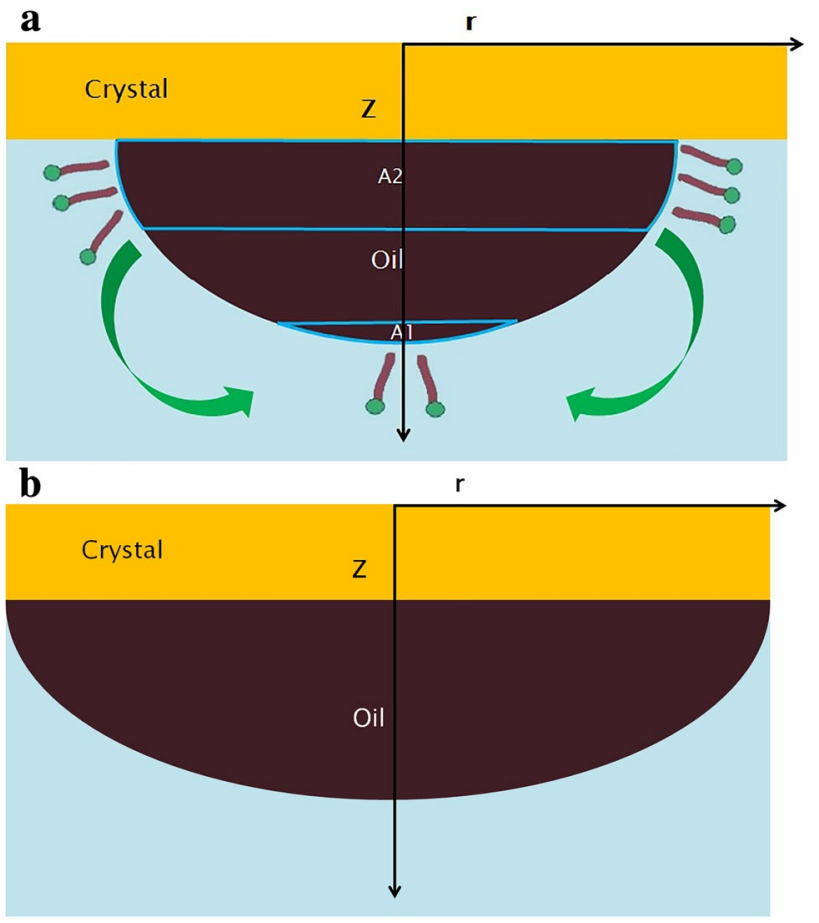

Fig. 6 a Left picture: Higher IFT at the droplet top generates Marangoni forces from the contact toward the top of the droplet. b Right picture: Surfactant absorption lowers the oil-silica crystal contact angle, inducing the spreading of the droplets over the silica surface

Here, $U_{z}$ and $U_{r}$ are the velocity components along the axial and radial directions as was shown in Fig. $6 a, b . \mu_{o}$ is the oil viscosity. The IFT gradient with respect to $r$ is proportional to the IFT gradient with respect to the surfactant concentration. The higher IFT gradient is supposed when the surfactant concentration, $C$, is higher and the radius of the oil drop, $R_{d}$, is lower. Since the IFT gradient with respect to $r$ can be predicted as:

$\frac{d \gamma_{o w}}{d r}=\frac{C}{R_{d}} \frac{d \gamma_{o w}}{d C}$

Replacing the logarithm of surfactant concentration in the Eq. (5) and inserting of the surface excess concentration, $\Gamma$, from the Eq. (3) into the rearranged equation gives the relationship between the IFT gradient with respect to $r$ and the surface excess concentration as:

$\frac{d \gamma_{o w}}{d r}=-\frac{R T \Gamma}{R_{d}}$

Hence, by replacing Eq. (6) into Eq. (4), the velocity of Marangoni flow will be related directly to the surface excess concentration by the following equation:

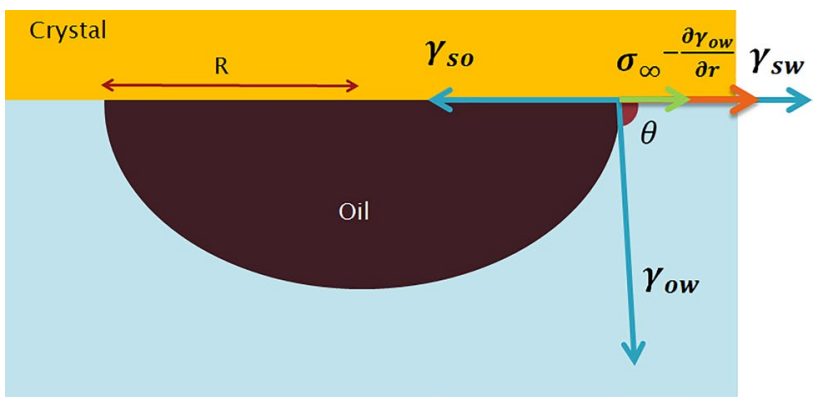

Fig. 7 Schematic diagram of different forces working along the contact line with their respective directions

$\frac{\partial U_{z}}{\partial r}+\frac{\partial U_{r}}{\partial z}=-\frac{R T \Gamma}{R_{d} \mu_{o}}$

A Schematic diagram of different forces working along the contact line with their respective directions is shown in Fig. 7. $\sigma_{\infty}$ is line tension corresponding to an infinitely large drop and supposed to be positive in Fig. 7. As the IFT gradient is as an extra tensile force on the three-phase contact line, for the equilibrium of the oil drop, IFT gradient should be included in the force balance of the horizontal direction. Applying IFT gradient in the force balance in the horizontal direction and replacing it from Eq. (6), gives the modified Eq. (2) as:

$\cos \theta_{\text {ow }}=\frac{\gamma_{\text {so }}-\gamma_{s w}}{\gamma_{\text {ow }}}-\frac{2 \pi R T \Gamma}{\gamma_{\text {ow }}}-\frac{\sigma}{\gamma_{\text {ow }}} \frac{1}{R_{d}}$

Plotting of $\cos \theta_{\text {ow }}$ versus $1 / R_{d}$ for injections with surfactants doesn't give a proper linear fit. The deviation can be corrected by considering the Tolman's correction [51, 52] as:

$\sigma=\sigma_{\infty}+\frac{c}{R_{d}}$

Replacing line tension in Eq. (8) with the Tolman's corrected line tension form gives a second-order correction to Young's equation as:

$\cos \theta_{\text {ow }}=\frac{\gamma_{\text {so }}-\gamma_{\text {sw }}}{\gamma_{\text {ow }}}-\frac{2 \pi R T \Gamma}{\gamma_{\text {ow }}}-\frac{\sigma_{\infty}}{\gamma_{\text {ow }}} \frac{1}{R_{d}}-\frac{c}{\gamma_{o w}} \frac{1}{R_{d}^{2}}$

The second order polynomial equations were fitted to the plots of $\cos \theta_{\text {ow }}$ versus $1 / R_{d}$ data for surfactant and combined surfactant and low salinity flooding experiments. Line tension to IFT ratios were calculated from the second coefficient of the regressed equation which are given in Table 7. The negative line tension to IFT ratios in Table 7 show negative line tensions in presence of surfactant solution. Table 7 also shows larger negative line tension to IFT ratios as the higher ion strength and calcium content 
Table 7 Line tension to IFT ratios for four crude oils and different surfactant systems

\begin{tabular}{lllll}
\hline Oil & $\mathrm{HS}_{2}-\mathrm{SDBS}(\mathrm{mm})$ & $\mathrm{HS}_{1}-\mathrm{LS}_{1}-\mathrm{SDBS}(\mathrm{mm})$ & $\mathrm{HS}_{2}-\mathrm{LS}_{1}-\mathrm{SDBS}(\mathrm{mm})$ & $\begin{array}{l}\mathrm{HS}_{2}-\mathrm{LS}_{1}- \\
\mathrm{SDBS} \\
(\mathrm{mm})\end{array}$ \\
\hline $\mathrm{A}$ & & & -0.04 \\
$\mathrm{~B}$ & -3.95 & -6.80 & -11.47 & -0.04 \\
$\mathrm{C}$ & -4.72 & -6.03 & - & -0.05 \\
$\mathrm{D}$ & -0.36 & -3.87 & -5.64 & -0.39 \\
$\begin{array}{c}\text { lonic strength } \\
\text { (mol/L) }\end{array}$ & -0.29 & -9.31 & -15.64 & 0.32 \\
$\begin{array}{l}\text { Remark } \\
\text { Rem }\end{array}$ & Non aged & 0.32 & 0.32 & Aged \\
\hline
\end{tabular}

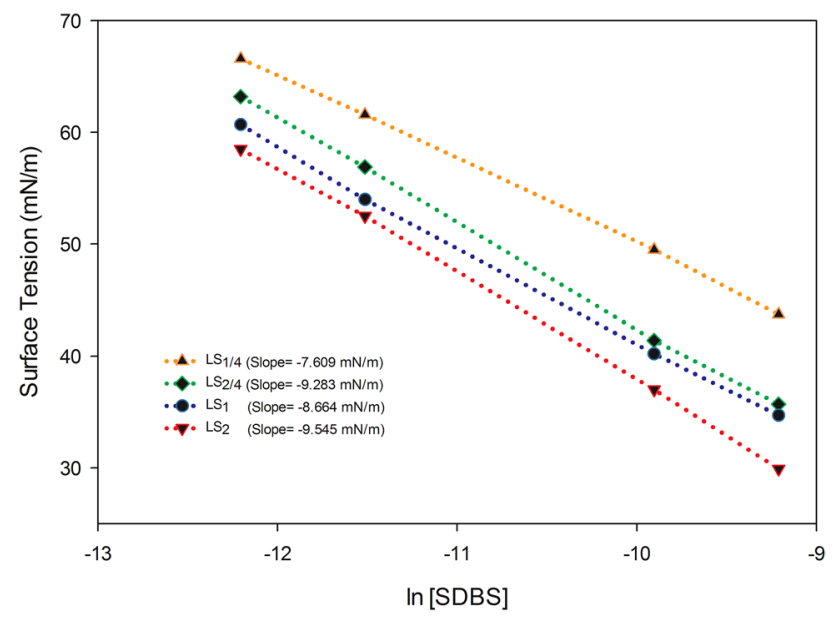

Fig. 8 Surface tension as a function of SDBS in different brine systems

present in brine. The reduction of the line tension to IFT ratios for surfactant injections at higher ion strength and calcium content is due to two different effects. First at early time, when the IFT gradient is increased, $\gamma_{s w}$, and $\gamma_{o w}$ are decreased, and $\gamma_{s o}$ is almost constant (Surfactant doesn't exist at the oil (solid interface), the line tension decreases and becomes more negative to balance the surface tensions at the three-phase contact line. Second, while the IFT is reduced due to the compression of the oillwater interface with higher amount of surfactant molecules. The combination of both effects reduces the value of the line tension to IFT ratio.

According to Eq. (2), as the initial contact angle between the oil and water is higher after aging the surface with oil, line tension to IFT ratio will increase as the oil-water contact angle corresponding to an infinitely large drop is approaching to $180^{\circ}$ in presence of surfactant. Therefore, the line tension to IFT ratios for the aged samples are higher than others and close to zero which indicates free movement of the contact line [24]. Surface tension was plotted versus surfactant concentration in different brine systems as shown in Fig. 8. The
Table 8 The $\Gamma$ values at different salinity conditions calculated by the Eq. (1)

\begin{tabular}{ll}
\hline Brine & $\begin{array}{l}\Gamma \times 10^{6} \\
\left(\mathrm{~mol} / \mathrm{m}^{2}\right)\end{array}$ \\
\hline $\mathrm{LS}_{1} / 4$ & 3.10 \\
$\mathrm{LS}_{2} / 4$ & 3.78 \\
$\mathrm{LS}_{1}$ & 3.53 \\
$\mathrm{LS}_{2}$ & 3.89 \\
\hline
\end{tabular}

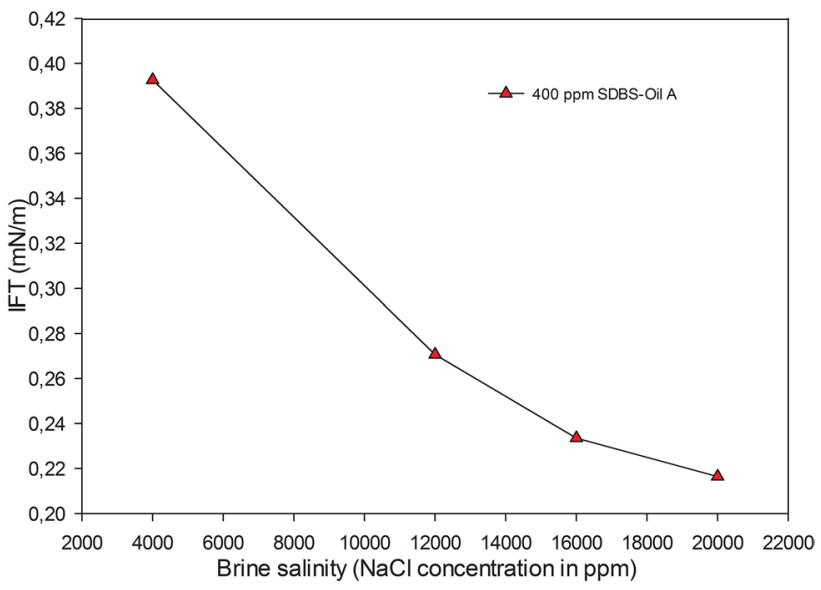

Fig. 9 IFT values between 400 ppm SDBS solution and different oils at $22^{\circ} \mathrm{C}$

surface excess concentration values listed in Table 8 which were calculated from the slope of the regressed straight lines in Fig. 8 by using the Eq. (3). Comparing the $\Gamma$ results at $\mathrm{LS}_{1} / 4$ (diluted $\mathrm{LS}_{1}$ by fourfolds) and $\mathrm{LS}_{1}$ indicates the higher amount of surfactant molecules presents at the interface when the salinity is higher. The higher $\Gamma$ value at higher ion strength can be explained by reduction of repulsion between the surfactant molecules and allowing them to approach closer to each other [53] which leads to lower IFT values [27] as was shown in Fig. 9. Compressing the oillwater interface with higher amount of surfactant molecules is stronger in presence of calcium ions [54,55]. Therefore at the same ion strength, e.g. comparing $\mathrm{LS}_{1} / 4$ and $\mathrm{LS}_{2} / 4$ or $\mathrm{LS}_{1}$ and 
$\mathrm{LS}_{2}$, the $\Gamma$ values are higher for the brine systems containing calcium.

For a very large drop (i.e., when $R_{d}$ approaches to infinity), the $R_{d}$ dependence terms in the right-hand side of Eq. (10), $-\frac{\sigma_{\infty}}{\gamma_{o w}} \frac{1}{R_{d}}-\frac{c}{\gamma_{o w}} \frac{1}{R_{d}^{2}}$, vanishes and by rearranging the equation, surface excess concentration can be obtained as

$\Gamma=\frac{\gamma_{o w}}{2 \pi R T}\left(\cos \theta_{\infty}-\cos \theta_{\text {ow }}\right)$

where $\theta_{\infty}$ is the contact angle corresponding to an infinitely large drop. Obtaining the $\cos \theta_{\text {ow }}$ from fitting the second order polynomial equation to the plot of $\cos \theta_{\text {ow }}$ versus $1 / R_{d}$ data and assuming IFT and $\theta_{\infty}$ to be $0.24 \mathrm{mN} / \mathrm{m}$ and $180^{\circ}$, respectively, the surface excess concentration $(\Gamma)$ is approximated from Eq. (11) to $3.9 \times 10^{-6} \mathrm{~mol} / \mathrm{m}^{2}$ for crude oil $A$ and $\mathrm{HS}_{2}-\mathrm{LS}_{1}-\mathrm{SDBS}$ system. This estimate agrees quite well with the surface excess concentration values listed in Table 8. The required time for the oil drop to gradually flatten out and spreading on the surface is defined as spreading time. Figure 10 shows a positive correlation between the spreading time and the line tension to IFT ratio. Comparing the graphs in Fig. 10 shows the shortest spreading times for the combined low salinity and surfactant

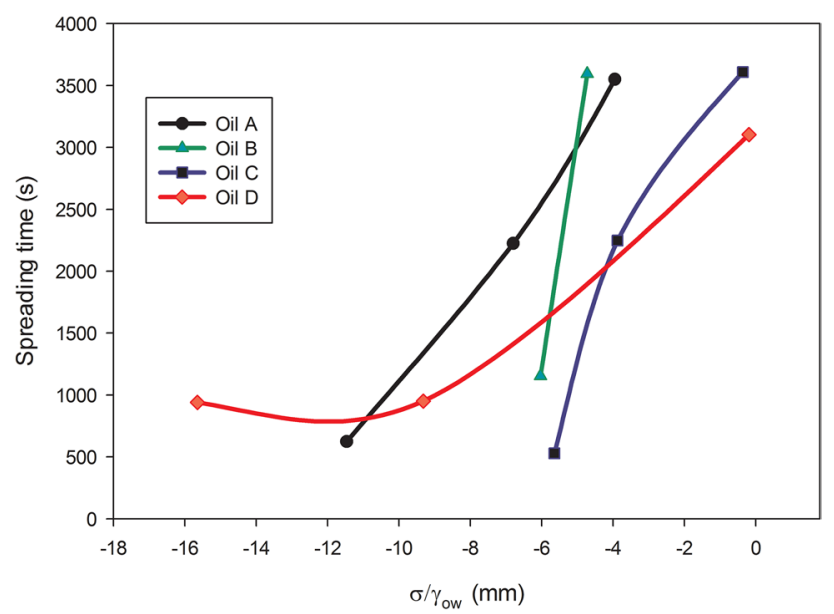

Fig. 10 Spreading time versus IFT ratios for four crude oils and $\mathrm{HS}_{2}-$ SDBS, $\mathrm{HS}_{1}-\mathrm{LS}_{1}-\mathrm{SDBS}$ and $\mathrm{HS}_{2}-\mathrm{LS}_{1}-\mathrm{SDBS}$ systems injection system with calcium $\left(\mathrm{HS}_{2}-\mathrm{LS}_{1}-\mathrm{SDBS}\right)$. The spreading time increased in the combined low salinity and surfactant injection system with sodium $\left(\mathrm{HS}_{1}-\mathrm{LS}_{1}-\mathrm{SDBS}\right)$ and reached the maximum value in the surfactant injection system $\left(\mathrm{HS}_{2}-\mathrm{SDBS}\right)$.

The work of adhesion which is the required work to separate a drop of liquid from the solid is related to the IFT and contact angle by Young-Dupre equation [56] as:

$W_{a}=\gamma_{\text {ow }}\left(1+\cos \theta_{\text {ow }}\right)$

Replacing the $\cos \theta_{\text {ow }}$ from the Eq. (11) into Eq. (12) gives:

$\mathrm{W}_{a}=\gamma_{\text {ow }}\left(1+\cos \theta_{\infty}-\frac{2 \pi R T \Gamma}{\gamma_{\text {ow }}}\right)$

Based on the Eq. (13), the lower IFT, the higher $\theta_{\infty}$, and the higher surface excess concentration results the lower adhesion work. Hence the spread oil on the surface develops a free oil film which can be removed easily from the surface by some viscos forces as the work of adhesion, $\mathrm{W}_{a}$ approaches to zero when the contact angle corresponding to an infinitely large drop, $\theta_{\infty}$, approaches to $180^{\circ}$.

The liberty of the spread oil drop was experimentally confirmed by conducting the same contact angle measurement on the $20^{\circ}$ tilted crystal. Injection of the combined surfactant and low salinity solution converted the oil drop to moveable oil film which was gradually moved up and produced by assistance of gravity force.

The core flooding results showing oil recovery of LSW-SF are given in Table 9. For high permeability, plugs 1 and 2 , the LSW-SF with calcium resulted in $4.6 \%$ of additional oil recovery from residual oil after LSWF (ROA-LSWF). For low permeability range, samples 3 and 4, also 3.4\% higher oil recovery was achieved with sample contained calcium, sample 3. Therefore, considering the effect of calcium, there is a good agreement between dynamic contact angle and core flooding results.

Most of the surfactant molecules stays in the aqueous phase at low salinity brine system and, therefore, only small quantity of surfactant has impact on the interface or oil phase. At high salinity brine, the surfactant molecules preferentially dissolve into the oil phase and, hence,

Table 9 Comparison of oil recoveries after sequential injection of LSWF and LSW-SF in core flooding tests

\begin{tabular}{llllllr}
\hline Plug No. & In-situ brine & $\begin{array}{l}\text { 1st injection } \\
\text { (LSWF) }\end{array}$ & $\begin{array}{l}\text { Residual oil saturation } \\
\text { after LSWF (\%) }\end{array}$ & $\begin{array}{l}\text { 2nd injection } \\
\text { (LSW-SF) }\end{array}$ & $\begin{array}{l}\text { Residual oil saturation } \\
\text { after LSW-SF (\%) }\end{array}$ & $\begin{array}{l}\text { Oil recovery of } \\
\text { LSW-SF (\%ROA- } \\
\text { LSWF) }\end{array}$ \\
\hline 1 & $\mathrm{HB}_{1}$ & $\mathrm{LB}_{1}$ & 37.2 & $\mathrm{~S}_{1}$ & 34.9 & 6.2 \\
2 & $\mathrm{HB}_{2}$ & $\mathrm{LB}_{2}$ & 36.3 & $\mathrm{~S}_{2}$ & 32.4 & 10.8 \\
3 & $\mathrm{HB}_{1}$ & $\mathrm{LB}_{1}$ & 42.5 & $\mathrm{~S}_{1}$ & 38.6 & 9.3 \\
4 & $\mathrm{HB}_{2}$ & $\mathrm{LB}_{2}$ & 42.9 & $\mathrm{~S}_{2}$ & 37.5 & 12.7 \\
\hline
\end{tabular}


a small amount stays in the aqueous phase or interface whereas the surfactant concentration is the same in oil and water phase at intermediate salt concentration [5].

As it was shown in Fig. 10 and Table 6, the combined surfactant and low salinity system, $\mathrm{HS}_{2}-\mathrm{LS}_{1}-\mathrm{SDBS}$, showed the shortest spreading time and expected to have the highest surface excess concentration which leads to the higher IFT gradient and Marangoni flow.

In our experiments, the combined surfactant and low salinity system, contains higher total salinity comparing to the other measurements but as the salinity is still lower than optimal salinity, lower line tension to IFT ratio was observed. In real case, as formation's brine usually consists of high salt concentration in many reservoirs, applying LSW-SF can lead to intermediate salinity brines and consequently better EOR conditions.

The results of the IFT measurements, the calculated surface excess concentrations, and core flooding tests are in agreement and consistent with the spreading times and line tension to IFT ratios obtained from the independent contact angle measurements, confirming that oil recovery increases as line tension to IFT ratio decreases. Considering line tension to IFT ratios through running the dynamic contact angle experiments offers a pretty fast technique of evaluating and comparing the vital experimental factors for EOR prior to conducting more time-consuming core displacement tests.

\section{Conclusions}

An experimental study has been carried out to investigate the dynamic contact angle alteration for combined low salinity brine injection and surfactant flooding on silica surface, which revealed the following conclusions.

Dynamic contact angle studies appear that slightly wettability alteration towards more water wet condition during LSWF measurements is governed by at least two factors including the expansion of the diffuse double layer between the silica surface and the oil interfaces as well as the stability of the water film by increasing the disjoining pressure. Expansion of the diffuse double layer is dominant when the acid/base interaction is acting in presence of sodium low salinity solution whereas increasing the disjoining pressure is leading when the ion-binding mechanism presents particularly in the calcium brine system.

Contradict to the general view that the wettability alteration to water wet condition is essential to EOR, the contact angle between oil and water can increase by injection of surfactant solutions which indicates the lower required adhesion work to separate the oil film from the surface.
The experimental contact angle data between oil and water were studied with the modified Young's equation, which considers the effect of line tension on the contact angle as a correction. The analysis of line tensions yields negative values for surfactant injections and positive line tensions for low salinity brine injections. The negative sign of the line tension leads to a lower stability limit for oil drop and shorter spreading time.

The ratio between line tension and IFT is a key parameter in determining the efficiency of the water/oil desorption process, with the spreading time decreasing and oil recovery increasing as larger negative line tension to IFT ratios achieved.

The results of contact angle measurement on the tilted crystal, IFT measurements, line tension to IFT ratio calculations, and core flooding tests has enabled us to confirm that the spread oil in presence of surfactant is a free oil and can be produced by assistance of some viscos forces. The oil spreading behavior is related to the IFT gradient and IFT reduction as was predicted by the developed equations.

Acknowledgements Open Access funding provided by NTNU Norwegian University of Science and Technology (incl St. Olavs Hospital - Trondheim University Hospital). The authors are very grateful for the financial support by our industrial partners Lundin Norge AS, Statoil, Det Norske Oljeselskap, GDF Suez, Unger Fabrikker AS and Forskningsrådet. Further we want to thank May Grete Sætran and Bicheng Gao for their help with the HPLC fractionation and Murside Kes and Sébastien Simon for their help with evaluating TAN and TBN of the crude oil. Also, we would like to thank Jens Norrman for inspiring and fruitful discussions and valuable suggestions.

Author contributions TT: had lead contribution in conducting experiments, analyzing the data and writing - review and editing. $\mathrm{HH}$ : had lead contribution in conducting experiments and writing-review and editing. TJ had contribution in conducting experiments and supporting contribution in writing. IKH had contribution in conducting experiments and supporting contribution in writing. BG had supporting contribution in conducting experiments, analyzing the data and writing - review and editing. OT had lead contribution in supervision, designing the study and supporting contribution in providing resources. $G \varnothing$ had lead contribution in supervision, designing the study, writing - review and editing and supporting contribution in providing resources.

Funding This study was funded by Lundin Norge AS, Statoil, Det Norske Oljeselskap, GDF Suez, Unger Fabrikker AS and Forskningsrådet.

\section{Compliance with ethical standards}

Conflict of interest On behalf of all authors, the corresponding author states that there is no conflict of interest.

Open Access This article is licensed under a Creative Commons Attribution 4.0 International License, which permits use, sharing, adaptation, distribution and reproduction in any medium or format, as long as you give appropriate credit to the original author(s) and the source, provide a link to the Creative Commons licence, and indicate if changes were made. The images or other third party material in this 
article are included in the article's Creative Commons licence, unless indicated otherwise in a credit line to the material. If material is not included in the article's Creative Commons licence and your intended use is not permitted by statutory regulation or exceeds the permitted use, you will need to obtain permission directly from the copyright holder. To view a copy of this licence, visit http://creativecommons .org/licenses/by/4.0/.

\section{References}

1. Wang L, Mohanty K (2014) Enhanced oil recovery in gasflooded carbonate reservoirs by wettability-altering surfactants. SPE J 20(01):60-69

2. Wang LMK (2013) Enhanced oil recovery in gas flooded carbonate reservoirs by wettability-altering surfactants. In: SPE conference, New Orleans, October 2013. SPE

3. Latil M (1980) Enhanced oil recovery. Éditions Technip

4. Stosur GJ (2003) EOR: Past, present and what the next 25 years may bring. In: SPE international improved oil recovery conference in Asia Pacific, 2003. Society of Petroleum Engineers

5. Donaldson EC, Chilingarian GV, Yen TF (1989) Enhanced oil recovery, processes and operations. II. Elsevier, Amsterdam

6. Green DW, Willhite GP (1998) Enhanced oil recovery, vol 6. Henry L. Doherty Memorial Fund of AIME, Society of Petroleum Engineers, Washington, DC

7. Olajire AA (2014) Review of ASP EOR (alkaline surfactant polymer enhanced oil recovery) technology in the petroleum industry: prospects and challenges. Energy 77:963-982

8. Zhou W, Dong M, Liu Q, Xiao H (2005) Experimental investigation of surfactant adsorption on sand and oil-water interface in heavy oil/water/sand systems. In: Canadian international petroleum conference. Petroleum Society of Canada

9. Kalaei MH, Green D, Willhite GP (2013) A new dynamic wettability-alteration model for oil-wet cores during surfactant-solution imbibition. SPE J 18(05):818-828

10. Qingjie L, Li L, Manli L (2004) Effect of wettability alteration on relative permeability curves for low permeability oil-wet reservoir rocks

11. Sheng J (2014) Critical review of low-salinity waterflooding. J Petrol Sci Eng 120:216-224

12. Thyne GD, Gamage S, Hasanka P (2011) Evaluation of the effect of low salinity waterflooding for 26 fields in Wyoming. In: SPE annual technical conference and exhibition. Society of Petroleum Engineers

13. Austad T, RezaeiDoust A, Puntervold T (2010) Chemical mechanism of low salinity water flooding in sandstone reservoirs. In: SPE improved oil recovery symposium. Society of Petroleum Engineers

14. Lager A, Webb KJ, Black C, Singleton M, Sorbie KS (2008) Low salinity oil recovery-an experimental investigation. Petrophysics 49(01):28-35

15. Ligthelm DJ, Gronsveld J, Hofman J, Brussee N, Marcelis F, van der Linde $\mathrm{H}$ (2009) Novel waterflooding strategy by manipulation of injection brine composition. In: EUROPEC/EAGE conference and exhibition. Society of Petroleum Engineers

16. McGuire P, Chatham J, Paskvan F, Sommer D, Carini F (2005) Low salinity oil recovery: an exciting new EOR opportunity for Alaska's North Slope. In: SPE western regional meeting, 2005. Society of Petroleum Engineers

17. Tang G-Q, Morrow NR (1999) Influence of brine composition and fines migration on crude oil/brine/rock interactions and oil recovery. J Petrol Sci Eng 24(2-4):99-111
18. Chavan M, Dandekar A, Patil S, Khataniar S (2019) Low-salinitybased enhanced oil recovery literature review and associated screening criteria. Petrol Sci 16:1344-1360

19. Aghaeifar Z, Strand S, Puntervold T (2019) Significance of capillary forces during low-rate waterflooding. Energy Fuels 33(5):3989-3997

20. Alagic $E$, Skauge $A$ (2010) Combined low salinity brine injection and surfactant flooding in mixed-wet sandstone cores. Energy Fuels 24(6):3551-3559

21. Hosseinzade Khanamiri $H$, Nourani $M$, Tichelkamp T, Stensen J $\AA$, Øye G, Torsæter O (2016) Low-salinity-surfactant enhanced oil recovery (EOR) with a new surfactant blend: effect of calcium cations. Energy Fuels 30(2):984-991

22. Hosseinzade Khanamiri $H$, Baltzersen Enge I, Nourani $M$, Stensen JÅ, Torsæter O, Hadia N (2016) EOR by low salinity water and surfactant at low concentration: impact of injection and in situ brine composition. Energy Fuels 30(4):2705-2713

23. Vijapurapu CS (2002) The effects of rock and fluids characteristics on reservoir wettability

24. Saini D, Rao DN (2009) Line tension-based modification of young's equation for rock-oil-brine systems. SPE Reservoir Eval Eng 12(05):702-712

25. Marmur A (1994) Contact angle hysteresis on heterogeneous smooth surfaces. J Colloid Interface Sci 168(1):40-46

26. Tichelkamp T, Vu Y, Nourani M, Øye G (2014) Interfacial tension between low salinity solutions of sulfonate surfactants and crude and model oils. Energy Fuels 28(4):2408-2414

27. Nourani M, Tichelkamp T, Gaweł B, Øye G (2016) Desorption of crude oil components from silica and aluminosilicate surfaces upon exposure to aqueous low salinity and surfactant solutions. Fuel 180:1-8

28. Hannisdal A, Hemmingsen PV, Sjöblom J (2005) Group-type analysis of heavy crude oils using vibrational spectroscopy in combination with multivariate analysis. Ind Eng Chem Res 44(5):1349-1357

29. Farooq U, Nourani M, Ivol F, Årrestad AB, Øye G (2019) Adsorption of crude oil components on mineral surfaces followed by quartz crystal microbalance and contact angle measurements: the effect of oil composition, simulated weathering and dispersants. Energy Fuels 33(3):2359-2365

30. Farooq U, Sjöblom J, Øye G (2011) Desorption of asphaltenes from silica-coated quartz crystal surfaces in low saline aqueous solutions. J Dispers Sci Technol 32(10):1388-1395

31. Nourani M, Tichelkamp T, Gaweł B, Øye G (2014) Method for determining the amount of crude oil desorbed from silica and aluminosilica surfaces upon exposure to combined low-salinity water and surfactant solutions. Energy Fuels 28(3):1884-1889

32. Gaweł B, Nourani M, Tichelkamp T, Øye G (2016) Influence of the wettability of particles on the morphology and stability of crude oil-particle aggregates in synthetic produced water. J Petrol Sci Eng 139:198-204

33. Grate JW, Dehoff KJ, Warner MG, Pittman JW, Wietsma TW, Zhang C, Oostrom M (2012) Correlation of oil-water and air-water contact angles of diverse silanized surfaces and relationship to fluid interfacial tensions. Langmuir 28(18):7182-7188

34. Rusanov A (1999) Classification of line tension. Colloids Surf A 156(1-3):315-322

35. Amirfazli A, Kwok D, Gaydos J, Neumann A (1998) Line tension measurements through drop size dependence of contact angle. J Colloid Interface Sci 205(1):1-11

36. Aveyard R, Clint JH, Nees D (1997) Theory for the determination of line tension from capillary condensation. J Chem Soc Faraday Trans 93(24):4409-4411 
37. Gaydos J, Neumann A (1987) The dependence of contact angles on drop size and line tension. J Colloid Interface Sci 120(1):76-86

38. Menger FM, Shi L, Rizvi SA (2009) Re-evaluating the Gibbs analysis of surface tension at the air/water interface. J Am Chem Soc 131(30):10380-10381

39. Moeini F, Hemmati-Sarapardeh A, Ghazanfari M-H, Masihi M, Ayatollahi S (2014) Toward mechanistic understanding of heavy crude oil/brine interfacial tension: the roles of salinity, temperature and pressure. Fluid Phase Equilib 375:191-200

40. Buckley J, Liu Y, Monsterleet S (1998) Mechanisms of wetting alteration by crude oils. SPE J 3(01):54-61

41. Liu Q, Dong M, Asghari K, Tu Y (2007) Wettability alteration by magnesium ion binding in heavy oil/brine/chemical/sand systems-Analysis of electrostatic forces. J Petrol Sci Eng 59(1-2):147-156

42. Collins S, Melrose J (1983) Adsorption of asphaltenes and water on reservoir rock minerals. In: SPE oilfield and geothermal chemistry symposium. Society of Petroleum Engineers

43. Pernyeszi T, Dékány I (2001) Sorption and elution of asphaltenes from porous silica surfaces. Colloids Surf A 194(1-3):25-39

44. Adejare OO, Nasralla RA, Nasr-EI-Din HA (2014) A procedure for measuring contact angles when surfactants reduce the interfacial tension and cause oil droplets to spread. SPE Reservoir Eval Eng 17(03):365-372

45. Ghannam MT (2003) Spreading behavior of crude oil over limestone substrate. J Colloid Interface Sci 262(2):435-441

46. Oren PE, Pinczewski WV (1994) The effect of wettability and spreading coefficients on the recovery of waterflood residual oil by miscible gasflooding. SPE Form Eval 9(02):149-156

47. Rao DN (1996) Wettability effects in thermal recovery operations. In: SPE/DOE improved oil recovery symposium. Society of Petroleum Engineers
48. Nikolov AD, Wasan DT, Chengara A, Koczo K, Policello GA, Kolossvary I (2002) Superspreading driven by Marangoni flow. Adv Coll Interface Sci 96(1-3):325-338

49. Majumder M, Rendall CS, Eukel JA, Wang JY, Behabtu N, Pint CL, Liu T-Y, Orbaek AW, Mirri F, Nam J (2012) Overcoming the "coffee-stain" effect by compositional Marangoni-flow-assisted drop-drying. J Phys Chem B 116(22):6536-6542

50. Hu H, Larson RG (2005) Analysis of the microfluid flow in an evaporating sessile droplet. Langmuir 21(9):3963-3971

51. Auer S, Frenkel D (2003) Line tension controls wall-induced crystal nucleation in hard-sphere colloids. Phys Rev Lett 91(1):015703

52. Berg JK, Weber CM, Riegler H (2010) Impact of negative line tension on the shape of nanometer-size sessile droplets. Phys Rev Lett 105(7):076103

53. Kumar MK, Mitra T, Ghosh P (2006) Adsorption of ionic surfactants at liquid-liquid interfaces in the presence of salt: application in binary coalescence of drops. Ind Eng Chem Res 45(21):7135-7143

54. Chen G, Wu X, Yang Z, Yu F, Hou J, Wang X (2007) Study of the effect of injection water quality on the interfacial tension of ASP/crude oil. J Can Petrol Technol 46(02):48-53

55. Talens F, Paton P, Gaya S (1998) Micelar flocculation of anionic surfactants. Langmuir 14(18):5046-5050

56. Schrader ME (1995) Young-dupre revisited. Langmuir 11(9):3585-3589

Publisher's Note Springer Nature remains neutral with regard to jurisdictional claims in published maps and institutional affiliations. 